\title{
The Thai Variant and the Distribution of Alleles of 6-Phosphogluconate Dehydrogenase and the Distribution of Glucose 6-Phosphate Dehydrogenase Deficiency in Thailand
}

\author{
Soodsarkorn Tuchinda, ${ }^{1}$ Donald L. Rucknagel, ${ }^{2}$ Supa Na-Nakorn, ${ }^{3}$ and Prawase Wasi ${ }^{3}$
}

Received 17 May 1968-Final 9 Aug. 1968

The samples were taken from 3185 subjects from ten provinces throughout Thailand. In 1577 males the frequency of glucose 6-phosphate dehydrogenase deficiency was $11.98 \%$. In the far south the gene frequency was $2.83 \%$; in the remainder of the country the frequency did not vary significantly about a mean of $13.76 \%$. The deficiency is of a severe type. The G6PD of all of the nondeficient individuals had the electrophoretic mobility of type $B$. The mean frequency of the A/B electrophoretic phenotype of 6-phosphogluconate dehydrogenase is $8.47 \%$. The maximum frequency was in central and southern Thailand with a decline to the north and northeast. $A$ variant form of 6-PGD, referred to as the Thai variant, has been found in which two additional electrophoretic components migrate anodally to the normal $A$ band, confirming that the molecule is at least a dimer. The hypothesis is advanced that erythrocyte 6-PGD is determined by two genetic loci, only one of which is translated in leukocytes.

A growing number of variants of the 6-phosphogluconate dehydrogenase (6-PGD) isozyme system are being detected, both as electrophoretic abnormalities and as heritable variations in total enzyme activity. The system is increasingly of interest because of a number of unique properties. Heterozygotes for structural mutants have two isozymic components in addition to the normal type A band, suggesting that the molecule is at least a dimer (Fildes and Parr, 1964). In erythrocytes the electrophoretic phenotype, to be described in detail below, does not conform to that expected on the

\footnotetext{
Supported by U.S. Army Contract DA-49-193 MD 2879, U.S.P.H.S. GM 09252, and U.S.P.H.S. 5-K3-GM-15325.

${ }^{1}$ Department of Pediatrics, Siriraj Hospital, Bangkok, Thailand.

2 Department of Human Genetics, University of Michigan Medical School, Ann Arbor, Michigan.

3 Department of Internal Medicine, Siriraj Hospital, Bangkok, Thailand.
} 
basis of genotype (Bowman et al., 1966), whereas the phenotype of the leukocyte consists of one or two major components compatible with the genotype (Parr and Fitch, 1967); these discrepancies have not heretofore been explained. The 6-PGD activity of leukocytes and erythrocytes appear to be derived from the same structural locus because a single mutant allele alters the isozymic phenotype of both.

The 6-PGD system is also of interest to the population geneticist because this locus has been polymorphic in nearly all populations studied to date, although the frequency of the most common structural variant-referred to variously as the $P G D^{\mathbf{B}}$, and more recently the $P G D^{\mathrm{C}}$ allele, by Parr and Fitch (1967) and as the $P d^{\mathbf{B}}$ allele by Bowman et al. (1966)-is not as variable (reviewed by Brewer, 1968; Carter et al., 1968) as are the major allelic frequencies of the related glucose 6-phosphate dehydrogenase (G6PD) system. The frequency of the $P d^{\mathbf{B}}$ allele varies between 0.02 (Dern et al., 1966; Parr, 1966) and 0.04 (Bowman et al., 1966) in Caucasian populations. In African Negroes the frequencies are somewhat higher, 0.06, in Uganda and Nigeria (Parr, 1966). The highest frequency reported to date, 0.247 , is in Bhutan (Carter et al., 1968).

Several variants of 6-PGD migrating cathodally to the normal or A type have been described (Parr and Fitch, 1967). In addition, two have been reported with mobilities faster than type $\mathrm{A}$ in alkaline $p \mathrm{H}$, the Richmond variant (Parr, 1966), and the so-called "Friendship" variant which is detectable only when NADP is omitted from the starch gel and electrophoresis buffers (Davidson, 1967). The following is a description of a third fast type, referred to as the Thai variant (Tuchinda et al., 1966), and a preliminary report of the frequency distribution of 6-PGD and G6PD alleles in ten provinces throughout Thailand. This is part of a large population genetics study to evaluate the role of selection and ethnic heterogeneity in the variation in frequency of hemoglobin E, thalassemia, and glucose 6-phosphate dehydrogenase deficiency (Gd) in Thailand. In addition, a hypothesis is advanced to account for the complexities of the electrophoretic pattern of 6-PGD.

\section{MATERIALS AND METHODS}

Venous blood samples were drawn in EDTA anticoagulant from rural villagers from ten regions throughout Thailand. From each village sample sizes of the order of 100 were collected, generally consisting of husband-wife pairs, by selecting at random a convenient proportion of those appearing at a village assembly and willing to cooperate. Samples were sent to Bangkok by rail and air in wet ice. As soon as practicable the cells were washed thrice with saline and stored at $4 \mathrm{C}$ as washed packed cells for up to 1 or 2 weeks. On the day of electrophoresis $10 \mathrm{~g}$ percent hemolysates were made and extracted with toluene. Electrophoresis was performed at $4 \mathrm{C}$ using vertical starch gel electrophoresis and the buffer system of Shows et al. (1964) in which NADP was present in the buffer trays and the gel. After electrophoresis at $4 \mathrm{C}$ for $16 \mathrm{hr}$ at $5 \mathrm{v} / \mathrm{cm}$, the gel slab was sliced with a wire and one half incubated for 6-10 hr at $37 \mathrm{C}$ with a substrate containing $20 \mathrm{mg}$ of 6-phosphogluconate, $10 \mathrm{mg}$ of NADP, $4 \mathrm{mg}$ of phenazine methosulfate, $150 \mathrm{mg}$ of magnesium chloride, and $10 \mathrm{mg}$ of nitroblue tetrazolium, 


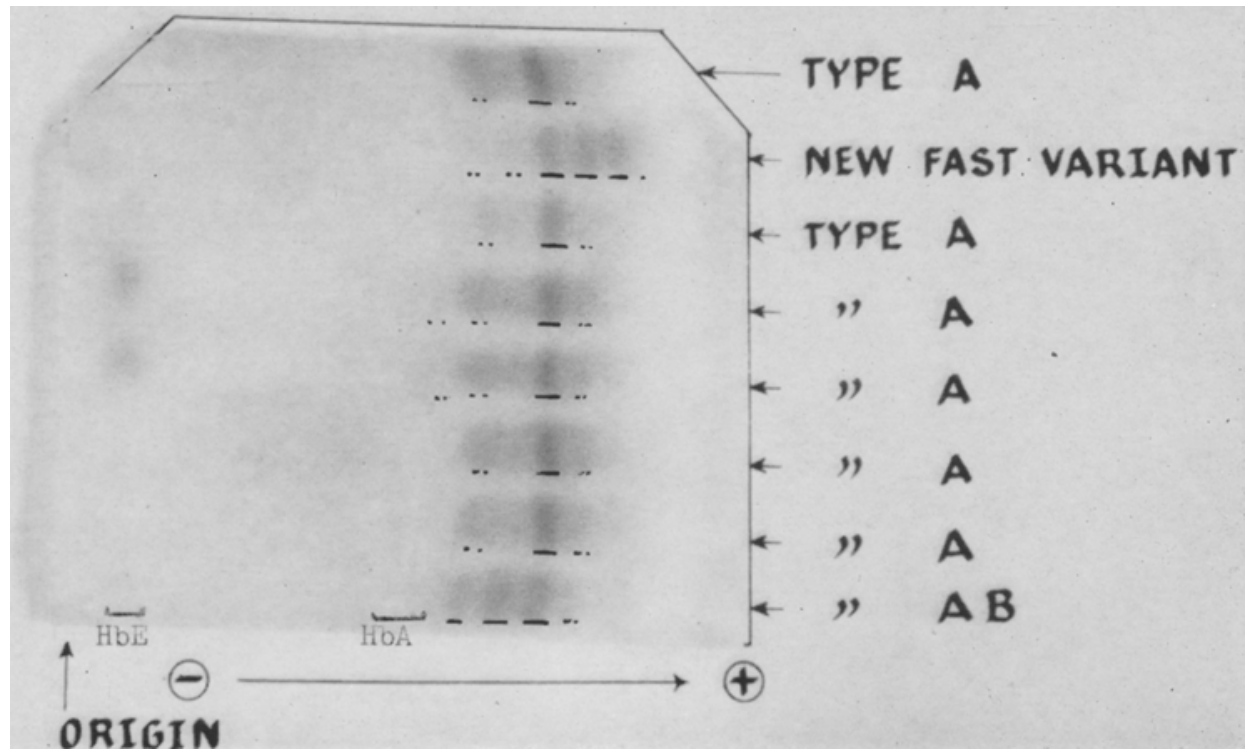

Fig. 1. Starch gel electrophoretic pattern at $p \mathrm{H} 8.6$ of 6-phosphogluconate dehydrogenase showing the A, A/B, and A/Thai phenotypes. The two components near the origin in the fourth and fifth wells from the top are hemoglobin $\mathrm{E}$; Hb $\mathrm{A}$ is observed immediately cathodal to the slowest (C) band of 6-PGD activity in the white destained area. The dots denote the minor components. 


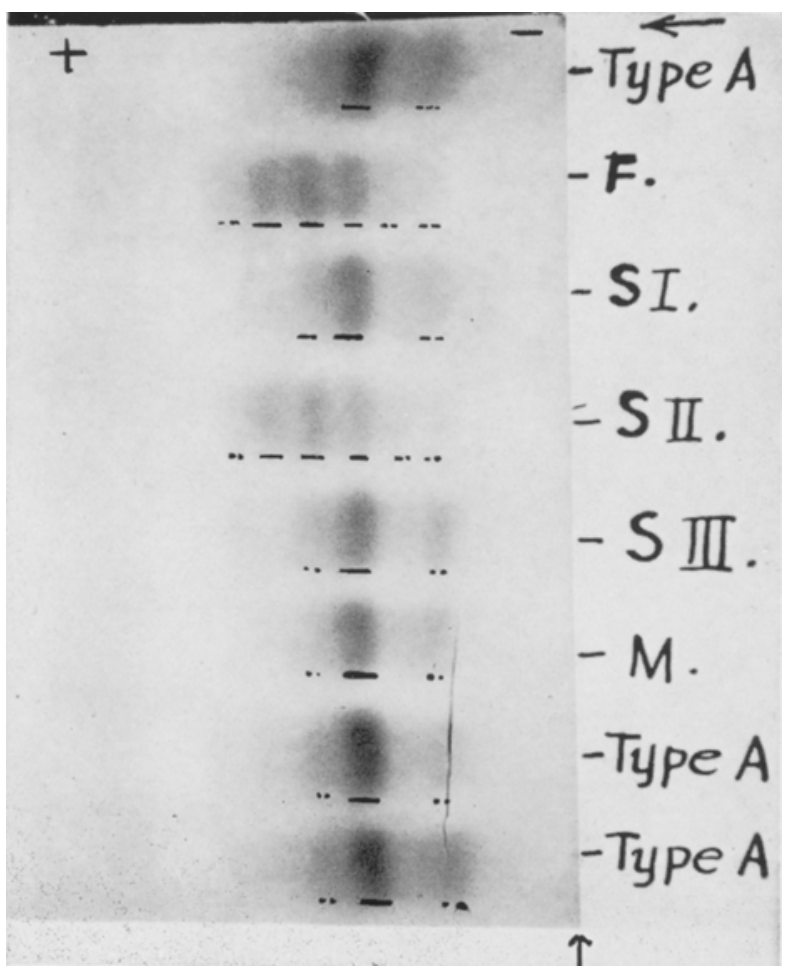

Fig. 2. Starch gel electrophoretic pattern at $p \mathrm{H} 8.6$ of the 6-PGD isozymes of the family with the Thai variant. The father $(\mathrm{F})$ and a sister (SII) of the proposita (shown in Fig. 1) had the variant, the mother (M) and the other two siblings (SI and SIII) were type A. The dots denote the minor components. Note that the anode is on the left. 
all in $100 \mathrm{ml}$ of $0.5 \mathrm{M}$ tris buffer at $p \mathrm{H} \mathrm{8.6.} \mathrm{The} \mathrm{other} \mathrm{half} \mathrm{of} \mathrm{the} \mathrm{gel} \mathrm{was} \mathrm{incubated} \mathrm{with}$ the same substrate mixture containing glucose 6-phosphate instead of 6-PG.

\section{RESULTS}

The predominant phenotype of 6-phosphogluconate dehydrogenase is the original type I of Fildes and Parr (1963) or the type A of Bowman et al. (1966) and Dern et al. (1966). The latter terminology will henceforth be used. In this phenotype, in addition to the anodally migrating major electrophoretic component, there are several more slowly moving minor fractions (Figs. 1-3). A cathodally (slowly) migrating component, referred to as the $\mathrm{C}$ band by Fildes and Parr (1964), comprises only a few percent of the total enzyme activity. A smaller minor component which is visible only in very concentrated hemolysates migrates between the $\mathrm{A}$ and $\mathrm{C}$ band. Another minor component migrates anodally to the major (A) band. Another minor component in the A phenotype, migrating cathodally to the $C$ band, is usually obscured by $\mathrm{Hb} A$ in our technique but is clearly visible in hemolysates from homozygotes for $\mathrm{Hb} \mathrm{E}$ (Fig. 1). This pattern of minor bands is comparable to that reported by Bowman et al. (1966).

The $\mathrm{AB}$ phenotype $(\mathrm{A} / \mathrm{B})$ is seen as a reduction in the intensity of the $\mathrm{A}$ band, with a somewhat heavier band (B) midway between the $\mathrm{A}$ and $\mathrm{C}$ bands and an increase in the intensity of the $C$ band compared with the minor amount present in the $A$ phenotype. The ratio of $\mathrm{A}: \mathrm{B}: \mathrm{C}$ is approximately 30:50:20 (Fig. 1). The B phenotype, shown by Bowman et al. (1966) to be the homozygous genotype for the B allele, was observed in one specimen as heavy $B$ and $C$ bands and persistence of a small amount of activity in the region of the $A$ band (Fig. 3 ).

In five individuals a heretofore undescribed variant form of 6-PGD, referred to as the Thai variant, was observed. In this the A band is reduced in intensity (Figs. 1, 2, and 3). Anodal to this are two major bands, the cathodal one overlying the fast minor component. These three bands were equidistant and their relative ratios, approximately 30:50:20, respectively. In addition, in this phenotype the $C$ band was apparently split into two components of equal intensity, one with the mobility of $\mathrm{C}$ and one lying between the $C$ and $A$ bands with the mobility of $B$ (Figs. 1, 2, and 3).

The Thai variant phenotype was found in three individuals in two different villages $30 \mathrm{~km}$ apart in Surin province (D, Fig. 4), $475 \mathrm{~km}$ northeast of Bangkok (black square, Fig. 4). Two of these were brother and sister. Although our records do not indicate that the third is a relative of the other two, they may be related. One individual with a similar variant was found near Pak Chong (C, Fig. 4) $175 \mathrm{~km}$ southwest of the former village and an additional example was found in Kanjanaburi Province (J, Fig. 4), nearly $600 \mathrm{~km}$ west of Surin and $125 \mathrm{~km}$ northwest of Bangkok. The variant bands of these individuals had identical mobilities when compared on the same gel. We have not been able to return to these diverse areas to determine whether all of these individuals are distantly related; their surnames are dissimilar.

Another presumed heterozygote for the Thai variant was ascertained through the Department of Pediatrics of Siriraj Hospital. The mobility of this variant was not 


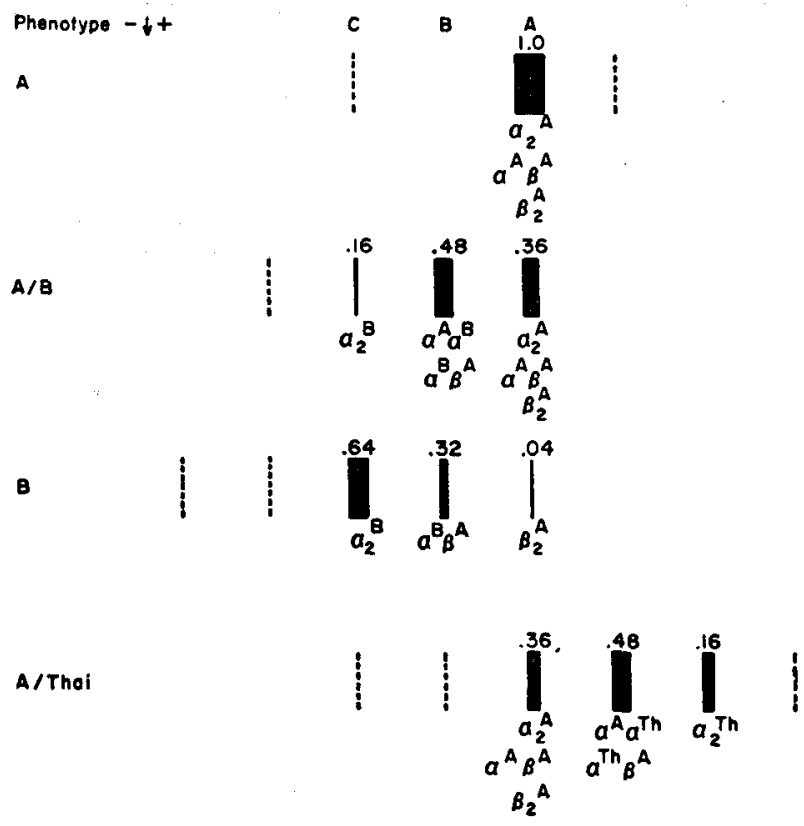

Fig. 3. Schematic diagram of the 6-PGD isozymes showing the contribution to each band by components with identical mobility produced by two hypothetical structural loci, $P d_{\alpha}$ and $P d_{\beta}$. The number above each major band denotes the expected fraction of the total activity represented by that band, assuming that 0.2 of the total activity is derived from $\beta^{\mathrm{A}}$ dimers, the remainder divided equally between $\alpha^{A}$ and $\alpha^{B}$. Thus, in the $A / B$ heterozygote the contribution to the $\mathrm{A}$ band by $\alpha_{2}{ }^{\mathrm{A}}, \alpha^{\mathrm{A}} \beta^{\mathrm{A}}$, and $\beta_{2}{ }^{\mathrm{A}}$ dimers would be $0.16,0.16$, and 0.04 , respectively. The dotted lines represent minor components comprising less than $5 \%$ of the total enzyme activity.

compared with that of the other five samples, however. The proposita was a 12-year-old girl with a severe anemia (hemoglobin $2.6 \mathrm{~g}$ percent, hematocrit $8 \%$ ) due to hookworm infestation. Following complete correction of the anemia with iron therapy there was no apparent change in the distribution of the various 6-PGD components. Her father and one sister had similar electrophoretic patterns. Her mother, a sister, and a brother had normal 6-PGD patterns (Fig. 2). This family lived in Nakorn Pathom, approximately $50 \mathrm{~km}$ west of Bangkok, midway between Kanjanaburi (J, Fig. 4) and Bangkok and $525 \mathrm{~km}$ west of Surin. To our knowledge, they are not related to any of the other individuals ascertained in the field survey.

Each of the cities and towns shown in Fig. 4 and Table IA represents a pool of samples from surrounding villages. The ten cities were in turn arranged according to the four geopolitical areas of Thailand (Table IA). 
Fig. 4. Map showing the distribution of provinces studied in Thailand. The letters correspond to the provincial capitals listed in Table IA. The solid black square is Bangkok.

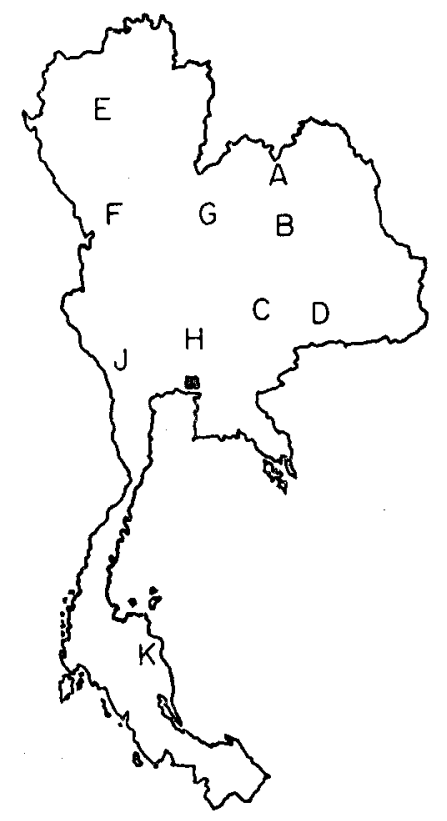

Table 1A. Frequencies of Glucose 6-Phosphate Dehydrogenase Deficiency and of the AB Phenotype of 6-Phosphogluconate Dehydrogenase in Provinces of Thailand

\begin{tabular}{|c|c|c|c|c|c|c|c|c|}
\hline & \multicolumn{3}{|c|}{ G6PD deficiency } & \multicolumn{5}{|c|}{ 6-PGD } \\
\hline & \multicolumn{3}{|c|}{ Males } & \multicolumn{5}{|c|}{ Sexes combined } \\
\hline & $\begin{array}{c}\text { No. } \\
\text { examined }\end{array}$ & $\begin{array}{c}\text { No. } \\
\text { deficient }\end{array}$ & $\begin{array}{c}\% \\
\text { deficient }\end{array}$ & $\begin{array}{c}\text { No. } \\
\text { examined }\end{array}$ & $\begin{array}{l}\text { No. } \\
\text { A/B }\end{array}$ & $\%$ & $\begin{array}{c}\text { Observed } \\
\text { No. B }\end{array}$ & $\begin{array}{c}\text { Expected } \\
\text { No. B }\end{array}$ \\
\hline \multicolumn{9}{|l|}{ Northeast } \\
\hline A. Udorn & 275 & 34 & 12.36 & 576 & 40 & 6.94 & $\mathbf{0}$ & 0.69 \\
\hline B. Chum Pae & 143 & 25 & 17.48 & 276 & 22 & 7.97 & $\mathbf{0}$ & 0.44 \\
\hline C. Pak Chong & 79 & 10 & 12.66 & 169 & 16 & 9.47 & 0 & 0.38 \\
\hline D. Surin & 152 & 24 & 15.78 & 318 & 22 & 7.43 & 1 & 0.41 \\
\hline Total & 649 & 93 & 14.33 & 1339 & 100 & 7.47 & 1 & 1.92 \\
\hline \multicolumn{9}{|l|}{ North } \\
\hline E. Chiengmai & 159 & 20 & 12.57 & 308 & 11 & 3.70 & 0 & 0.10 \\
\hline F. Tak & 194 & 23 & 11.86 & 409 & 41 & 10.02 & 0 & 1.0 \\
\hline G. Lom Sak & 129 & 19 & 14.73 & 253 & 32 & 12.65 & 0 & 1.0 \\
\hline \multirow{2}{*}{\multicolumn{9}{|c|}{ Central }} \\
\hline & & & & & & & & \\
\hline H. Saraburi & 106 & 15 & 14.15 & 211 & 26 & 12.32 & 0 & 0.80 \\
\hline J. Kanjanaburi & 93 & 12 & 12.90 & 185 & 21 & 11.35 & 0 & 0.60 \\
\hline Total & 199 & 27 & 13.55 & 396 & 47 & 11.84 & 0 & 1.40 \\
\hline \multirow{2}{*}{\multicolumn{9}{|c|}{$\begin{array}{l}\text { South } \\
\text { K. Nakorn }\end{array}$}} \\
\hline & & & & & & & & \\
\hline Srithamaraj & 247 & 7 & 2.83 & 480 & 39 & 8.12 & $\mathbf{0}$ & 0.79 \\
\hline Grand total & 1577 & 189 & 11.98 & 3185 & 270 & 8.47 & 1 & 6.21 \\
\hline
\end{tabular}


The frequency of the A/B phenotype of the autosomal 6-PGD system did not differ in males and females in any of the ten locations. The data for males and females were combined in Table IA and Fig. 4. The mean frequency of the A/B type was $8.47 \%$ in the entire study, most of the remainder being type $\mathrm{A}$. The highest frequencies of type $\mathrm{A} / \mathrm{B}$, approximately $12 \%$, were found in central and north central Thailand (G, H, and J, Fig. 4 and Table IA). From there the frequency fell off to approximately $7 \%$ in northeastern Thailand, 3.7\% in Chiengmai in northern Thailand (E, Fig. 4), and $8.1 \%$ in the far south at Nakorn Srithamaraj (K). The gradients to the north and northeast are statistically significant (Table IB). Although hill tribe admixture might account in part for the low frequency in Chiengmai, it cannot be the sole reason since hill tribesmen are also included in the samples from Lom Sak (G) and Tak (F).

Only one example of type B was detected. The cumulative number expected in the entire study was 6.2 (Table IA). In no single area was the departure from HardyWeinberg equilibrium significant. When the data from all areas were pooled, the departure due to deficiency of type B was significant at the 0.05 level $\left(\chi^{2}=4.27\right.$; d.f. = 1). Misclassification of $B$ as type $A / B$ could not be excluded. No samples deficient in 6-PGD activity (Brewer and Dern, 1964) were found.

In all of the males with detectable G6PD activity the mobility on starch gel electrophoresis was identical to that of the B electrophoretic type of Caucasians. The electrophoretic patterns of the deficient males showed virtually no enzymatic activity. No other G6PD variants were detected. The frequency of G6PD deficiency in males only is presented since this is equivalent to gene $\left(G d^{-}\right)$frequency in this sex-linked system and since the electrophoretic system employed did not allow detection of a sufficient proportion of heterozygous-deficient females. The highest frequency of $\mathrm{Gd}^{-}$ found was in northeastern Thailand; Chum Pae, $80 \mathrm{~km}$ west of Khon Kaen (B, Fig. 4)

Table IB. Statistical Analysis of Frequencies of Above Populations

\begin{tabular}{lccc}
\hline \multicolumn{1}{c}{ Comparison } & $\chi^{2}$ & d.f. & $P$ \\
\hline \multicolumn{4}{c}{ G6PD deficiency } \\
Northeast heterogeneity & 2.47 & 3 & \\
North heterogeneity & 0.59 & 2 & \\
Northeast vs. north & 0.48 & 1 & \\
South vs. central & 18.03 & 1 & $<0.001$ \\
\multicolumn{5}{c}{ 6-PGD type A/B } \\
Northeast heterogeneity & 2.68 & 6 & \\
North heterogeneity & 16.18 & 2 & $<0.001$ \\
Northeast vs. north & 1.09 & 1 & \\
Northeast vs. central & 7.63 & 1 & $<0.01$ \\
Northeast vs. south & 0.2 & 1 & $>0.05$ \\
North vs. central & 3.34 & 1 & \\
North vs. south & 0.18 & 1 & $>0.05$ \\
South vs. central & 3.43 & 1 & \\
& & & \\
\hline
\end{tabular}


is in the center of the region (17.48\%) and Surin (D, Fig. 4$)$ is near the Cambodian border $(15.78 \%)$. The differences within and between the north, central, and northeastern regions were not significant, however (Table IB). In southern Thailand, in the vicinity of Nakorn Srithamaraj, midway down the Malayan Peninsula, the frequency of $\mathrm{Gd}^{-}$was significantly lower (Table IB) than in the other three regions $(2.83 \%)$.

\section{DISCUSSION}

In the 6-phosphogluconate dehydrogenase electrophoretic patterns the distribution of major components in both the A/B, Richmond, and A/Thai phenotypes suggests that the 6-PGD molecule is composed of at least two subunits under the control of one locus, as proposed by Fildes and Parr (1964), and thus the middle band in all three phenotypes may be a hybrid molecule. The apparent simplicity of these observations is confounded by the demonstration in B homozygotes of major amounts of both the $\mathrm{B}$ and $\mathrm{C}$ components and persistence of some of the A component (Bowman et al., 1966; Parr, 1966) in excess of what one might expect if it were analogous to the minor component migrating anodally to the A band. These complexities can be accounted for if each of the major 6-PGD bands is composed of dimers of subunits derived from two different genetic loci, say $\alpha$ and $\beta$, of identical electrophoretic mobility and which combine at random. Thus, the A band would be composed of $\alpha_{2}{ }^{\mathrm{A}}$, $\beta_{2}{ }^{A}$, and $\alpha^{\mathbf{A}} \beta^{\mathbf{A}}$ molecules (Fig. 3), the superscript connoting identical mobilities. If the $B$ gene is a mutant of one of these, say the $P d_{\alpha}$ locus, an $\mathrm{A} / \mathrm{B}$ heterozygote $\left(P d_{\alpha}^{\mathbf{A}} / P d_{\alpha}^{\mathrm{B}}\right)$ would remain homozygous at the $P d_{\beta}$ locus $\left(P d_{\beta}^{\mathrm{A}} / P d_{\beta}^{\mathrm{A}}\right)$. The $\mathrm{B}$ band in $\mathrm{A} / \mathrm{B}$ heterozygotes would therefore be composed of $\alpha^{\mathrm{A}} \alpha^{\mathbf{B}}$ and $\alpha^{\mathrm{B}} \beta^{\mathrm{A}}$ molecules. The increase in the $\mathrm{C}$ band would be due to the formation of $\alpha_{2}{ }^{\mathrm{B}}$ dimers. Assuming that $20 \%$ of the 6-PGD activity is derived from the $\beta$-locus and that the remainder is contributed equally by the $\alpha$-alleles ( $\alpha^{\mathbf{A}}$ and $\alpha^{\mathrm{B}}$ ), the distribution of activity among the $\mathrm{A}, \mathrm{B}$, and $\mathrm{C}$ bands in an $\mathrm{A} / \mathrm{B}$ heterozygote would be $0.36,0.48$, and 0.16 , respectively, calculated from a simple trinomial distribution.

In the homozygous $\mathrm{B}$ phenotype $\left(P d_{\alpha}^{\mathrm{B}} / P d_{\alpha}^{\mathrm{B}}\right)$, the $\mathrm{A}$ band would be composed solely of $\beta_{2}{ }^{A}$ dimers, the $B$ band of $\alpha^{B} \beta^{A}$, and the $C$ band of $\alpha_{2}{ }^{B}$ dimers. Thus, in the homozygous $B$ phenotype, if the ratio of $\alpha^{B}$ and $\beta^{A}$ synthesis is $80: 20$, the ratio $\mathrm{A}: \mathrm{B}: \mathrm{C}$ bands would be $0.04: 0.32: 0.64$, respectively. Similarly, in the A/Thai phenotype the first band anodal to the $A$ band would be composed of $\alpha^{A} \alpha^{\text {Thai }}$ and $\alpha^{\text {Thai }} \beta^{A}$ dimers and the fastest band solely of $\alpha_{2}{ }^{\text {Thai }}$ dimers. The distribution of bands in the A/Thai phenotype is also consistent with production of $\alpha^{\mathrm{A}}, \alpha^{\text {Thai }}$, and $\beta^{\mathrm{A}}$ subunits in the ratio of $4: 4: 2$. Proceeding anodally from the $A$ band the expected ratio of band densities is approximately $0.36: 0.48: 0.16$, respectively, similar to that observed. If this hypothesis proves to be correct, the $\beta$ locus must be presumed to be nonfunctioning in leukocytes since the 6-PGD phenotype of white cells is compatible with only the same $P d_{\alpha}$ locus producing a dimer (Parr and Fitch, 1967).

The above hypothesis is not inconsistent with the combinations of quantitative and structural mutants, the so-called Newham variant (Parr and Fitch, 1967). At first glance it is inconsistent with the Whitechapel variant in which erythrocyte 6-PGD activity is only $3 \%$ of normal and virtually no 6-PGD activity is allegedly seen on the 
starch gel (Parr and Fitch, 1967). A regulator gene mechanism to explain this variant has not been excluded, however. Nor is it clear that with the technique employed the A band $\left(\beta_{2}{ }^{A}\right)$ would have been detected in the Whitechapel variant, if in fact it is present. The minor bands migrating in the $\mathrm{B}$ and $\mathrm{C}$ position in type $\mathrm{A}$ are displaced cathodally in types $A / B$ and $B$ and anodally in the A/Thai genotype. These displacements suggest that the minor components share at least one subunit with the major components. The nature of the minor components is otherwise unclear; they may be due to still other minor loci $(\gamma, \delta$, etc.) which produce subunits which polymerize with the major subunits, analogous to the $\delta$-chains of hemoglobin $\mathrm{A}_{2}$. They may also reflect varying stages of polymerization, conformational isomerization, or epigenetic alteration of the major components; although these alternatives are not differentiable by the data at hand, the lack of understanding of the minor components does not vitiate the hypothesis advanced in this report.

The Thai variant is different from the "Friendship" variant described by Davidson (1967); the latter is detected only if NADP is omitted from the starch gel buffer. Although the Thai variant appears similar to the Richmond phenotype found in England (Parr, 1966), the two variants almost certainly arose as independent mutations and are most likely due to different amino acid substitutions with similar charge differences, analogous to the heterogeneity of the hemoglobins D (Benzer et al., 1958). Since Surin and Pak Chong, east of Bangkok, and Kanjanaburi and Nakorn Pathom, to the west of Bangkok, are along natural routes of migration toward Bangkok, it is not unreasonable to assume that the families in each area are related. It seems improbable, however, that the families in all four areas have a common ancestor; therefore, it cannot be assumed that all four examples of the Thai variant have in fact the same amino acid substitution even though they may have similar electrophoretic mobilities. Should the same amino acid substitution be found in all of these variants, a remarkable dispersion at low frequency of a single mutation across the breadth of Thailand would be suggested.

A large amount of data suggests that the high frequency of the gene for sickle cell hemoglobin $\left(\mathrm{Hb}_{\beta}{ }^{\mathbf{S}}\right)$ in Africa is the result of selection mediated by falciparum malaria (reviewed in Rucknagel and Neel, 1961; and Allison, 1964). A correlation between the frequency of the $H b_{\beta}{ }^{\mathrm{S}}$ and glucose 6-phosphate dehydrogenase $\left(G d^{-}\right)$ genes suggests that polymorphism of the latter is also related to endemicity of malaria (Motulsky and Campbell-Kraut, 1961). Similarly, the cline in $H b_{\beta}{ }^{\mathbf{E}}$ frequency from $25 \%$ in northeastern Thailand to approximately $5 \%$ in the north and central areas has been attributed to selection by falciparum malaria (Kruatrachue et al., 1962; Flatz et al., 1964). The cline in the frequency of the A/B phenotype of 6-PGD is approximately the reverse of the $H b_{\beta}{ }^{\mathrm{E}}$ cline, suggesting that the variation in both is due to migration from the northeast rather than gene flow on a wave of selection pressure. Alternatively, selection could favor both the $H b_{\beta}{ }^{\mathrm{E}}$ and $P d^{\mathrm{A}}$ alleles in the northeast. Differentiation of these hypotheses may be possible when frequencies of the remaining genetic systems examined in this study are determined.

The apparently complete absence of G6PD activity in the electrophoretic pattern of deficient males in Thailand suggests that the deficiency is of a severe type, analogous to the Mediterranean variants of Caucasians (Kirkman et al., 1964). This observation 
is not sufficient to differentiate the deficiency in Thailand from the Canton variant which has been detected in Chinese (Kirkman et al., 1964), if, indeed, the deficiency in Thailand is either of these types.

G6PD deficiency is widely distributed in Thailand. The frequencies obtained in this study are comparable to those described in the same areas in other reports (Kruatrachue et al., 1962; Flatz and Sringam, 1963, 1964; Thirayothin and Sitachitt, 1964; Wasi et al., 1967). Although the differences in frequency of $G d^{-}$observed in this study in northern, northeastern, and central Thailand were not statistically significant, differences may yet appear when corrections are applied for variation in ethnic origin, population migration, and relatedness of individuals within each area. The very low frequency of $G d^{-}$in southern Thailand has heretofore not been reported and is upon superficial examination difficult to reconcile with a high prevalence of falciparum malaria in this region. One possible explanation is that the lower frequency is due to admixture with the Islamic population of the Malayan Peninsula who are also present in southern Thailand.

Flatz and Sringam (1964) believe that the correlation of $\mathrm{Gd}^{-}$with altitude is better than that with ethnic origin or geographic location and attribute this to selection pressure by malaria. Wasi et al. have found that $H b_{\beta}^{\mathrm{E}}$ and $\beta$-thalassemia gene frequencies are reciprocally related in northeastern Thailand but the sum of the two did not vary, whereas significant differences were observed in the frequency of $\mathrm{Gd}^{-}$. This observation, plus the dissociation in $G d^{-}$and the 6-PGD type A/B phenotype in this study, cannot be easily reconciled with variation in malaria endemicity and suggest that the genetic structure of Thailand may, indeed, be as complex as its complicated history implies. This, plus similar dissociations in Greece (Stamatoyannopoulos and Fessas, 1964) and Cyprus (Plato et al., 1964), indicates that the prevalence of these genes in Thailand cannot yet be accepted as proof of the hypothesis that malaria is the selective force.

\section{ACKNOWLEDGMENTS}

The authors gratefully acknowledge the logistic support of the SEATO Medical Research Laboratory, Bangkok, and the assistance of Dr. Kempthorn Swankij, former Director General, Department of Health of Thailand, and the many provincial health officers who cooperated with this study. We thank Miss Floretta Reynolds and Miss Somporn Samerong who performed the laboratory analyses and acknowledge the advice of Dr. Richard Tashian in setting up the technique.

\section{REFERENCES}

Allison, A. C. (1964). Polymorphism and natural selection in human populations. Cold. Spr. Harb. Symp. Quant. Biol. 29: 137.

Benzer, S., Ingram, V. M., and Lehmann, H. (1958). Three varieties of haemoglobin D. Nature (London) 182: 852.

Bowman, J. E., Carson, P. E., Frischer, H., and de Gorey, A. L. (1966). Genetics of starch-gel electrophoretic variants of human 6-phosphogluconic dehydrogenase: population and family studies in the United States and Mexico. Nature 210: 811. 
Brewer, G. J. (1968). 6-Phosphogluconate dehydrogenase and glutathione reductase. In Biochemical Methods in Red Cell Genetics. Edited by J. Yunis. New York, Academic Press.

Brewer, G. J., and Dern, R. J. (1964). A new inherited enzymatic deficiency of human erythrocytes: 6-phosphogluconate dehydrogenase deficiency. Am. J. Human Genet. 16: 472.

Carter, N. D., Fildes, R. A., Fitch, L. I., and Parr, C. W. (1968). Genetically determined electrophoretic variations of human phosphogluconate dehydrogenase. Acta Genet. Basel 18: 109.

Davidson, R. G. (1967). Electrophoretic variants of human 6-phosphogluconate dehydrogenase: Population and family studies and description of a new variant. Ann. Human Genet. $30: 355$.

Dern, R. J., Brewer, G. J., Tashian, R. E., and Shows, T. B. (1966). Hereditary variation of erythrocytic 6-phosphogluconate dehydrogenase. J. Lab. Clin. Med. 67: 255.

Fildes, R. A., and Parr, C. W. (1963). Human red-cell phosphogluconate dehydrogenases. Nature (London) 200: 890 .

Fildes, R. A., and Parr, C. W. (1964). Various forms of human erythrocyte phosphogluconate dehydrogenase. Proc. VIth Intern. Congr. Biochem. (Abstr.) III-17, 229.

Flatz, G., and Sringam, S. (1963). Malaria and glucose-6-phosphate dehydrogenase deficiency in Thailand. Lancet 2: 1248.

Flatz, G., and Sringam, S. (1964). Glucose-6-phosphate dehydrogenase deficiency in different ethnic groups in Thailand. Ann. Human Genet. London 27: 315.

Flatz, G., Pik, C., and Sundharagiati, B. (1964). Malaria and haemoglobin E in Thailand. Lancet 2: 385.

Kirkman, H. N., McCurdy, P. R., and Naiman, J. L. (1964). Functionally abnormal glucose-6phosphate dehydrogenases. Cold Spr. Harb. Symp. Quant. Biol. 29 : 391.

Kruatrachue, M., Na-Nakorn, S., Charoenlarp, P., and Suwanakul, L. (1961). Haemoglobin E and malaria in Southeast Thailand. Ann. Trop. Med. Parasit. 55: 468.

Kruatrachue, M., Charoenlarp, P., Chongsuphajaisiddhi, T., and Harinasuta, C. (1962). Erythrocyte glucose-6-phosphate dehydrogenase and malaria in Thailand. Lancet 2: 1183.

Motulsky, A. G., and Campbell-Kraut, J. M. (1961). Population genetics of glucose-6-phosphate dehydrogenase deficiency of the red cell. In Proceedings of the Conference on Genetic Polymorphisms and Geographic Variations in Disease. Edited by B. S. Blumberg, Grune and Stratton, pp. 159-191.

Parr, C. W. (1966). Erythrocyte phosphogluconate dehydrogenase polymorphism. Nature 210: 487.

Parr, C. W., and Fitch, L. I. (1967). Inherited quantitative variations of human phosphogluconate dehydrogenase. Ann. Human Genet. 30: 339.

Plato, C. C., Rucknagel, D. L., and Gershowitz, H. (1964). Studies on the distribution of glucose-6phosphate dehydrogenase deficiency, thalassemia, and other genetic traits in coastal and mountain villages of Cyprus. Am. J. Human Genet. 16: 267.

Rucknagel, D. L., and Neel, J. V. (1961). The hemoglobinopathies. Prog. Med. Genet. $1: 158$.

Shows, T. B., Jr., Tashian, R. E., Brewer, G. J., and Dern, R. J. (1964). Erythrocyte glucose-6phosphate dehydrogenase in Caucasians: New inherited variant. Science 145: 1056.

Stamatoyannopoulos, G., and Fessas, Ph. (1964). Thalassemia, glucose-6-phosphate dehydrogenase deficiency, sickling and malarial endemicity in Greece: A study of five areas. Brit. Med. J. 1: 875 .

Thirayothin, P., and Sitachitt, P. (1964). Ann. Progr. Rept. SEATO Med. Res. Lab., Bangkok.

Tuchinda, S., Rucknagel, D. L., Na-Nakorn, S., and Wasi, P. (1966). Glucose-6-phosphate dehydrogenase and 6-phosphogluconate dehydrogenase isozyme frequencies in Thailand. Abstracts, XI Congr. Internat. Soc. Haemat., 255.

Wasi, P., Na-Nakorn, S., and Suingdumrong, A. (1967). Studies of the distribution of haemoglobin E, thalassemias and glucose-6-phosphate dehydrogenase deficiency in Northeastern Thailand. Nature (London) 214: 501. 